\title{
The Biosynthesis by Pneumococcus of a Non-Reducing Disaccharide from Uridine Diphosphoglucose
}

\author{
By EVELYN E. B. SMITH* AND G. T. MILLS* \\ Department of Medicine, State University of Nerw York \\ Downstate Medical Center, Brooklyn 3, New York, U.S.A.
}

(Received 2 April 1963)

\begin{abstract}
SUMMARY
A particulate enzyme fraction from type VIII Pneumococcus obtained by centrifugation of disrupted organisms between 30,000 and $140,000 \mathrm{~g}$ synthesized a non-reducing disaccharide from uridine diphosphoglucose (UDPG). The structure proposed for the material synthesized is glucopyranosyl-glucopyranoside, in which at least one of the linkages is of the $\beta$ configuration. The reaction may be formulated as: UDPG + UDPG $\rightarrow$ glucopyranosyl-glucopyranoside. The reaction was not type-specific and was also found with particulate fractions from pneumococci of types II and III.
\end{abstract}

\section{INTRODUC'TION}

The capsular polysaccharide of type III pneumococci is a polymer of cellobiuronic acid ( $\beta$-1,4-glucuronosido-glucose); the biosynthesis of this polysaccharide from uridine diphosphoglucose (UDPG) and uridine diphosphoglucuronic acid (UDPGA) is well defined (Smith, Mills, Bernheimer \& Austrian, 1960; Smith, Mills \& Bernheimer, 1961). The mechanisms involved in the biosynthesis of the capsular polysaccharides of pneumococci of types I and VIII are being studied (Smith, Galloway \& Mills, 1961; Mills \& Smith, 1962); these investigations include the isolation and identification of small oligosaccharide molecules formed from uridine diphosphoglycosyl substrates. The first of these reactions, described here, is the biosynthesis of a non-reducing disaccharide from UDPG.

\section{METHODS}

Organism used. This was Streptococcus pneumoniae type VIII. The organism was grown in 1 l. lots of Difco brain + heart infusion medium $(3.7 \%, \mathrm{w} / \mathrm{v} ; \mathrm{pH} 7 \cdot 4)$ containing $\mathbf{0 \cdot 1} \%$ neopeptone. After incubation of the culture for $16 \mathrm{hr}$., glucose was added to $1 \%(\mathrm{w} / \mathrm{v})$; the acid formed on subsequent incubation was neutralized with $3 \mathrm{~N}-\mathrm{NaOH}$. Incubation was at $36 \cdot 5^{\circ}$ and the organisms were collected by centrifugation at $20,000 \mathrm{~g}$ for $20 \mathrm{~min}$. at $3^{\circ}$, when $70 \%$ of the added glucose had disappeared.

The particulate enzyme fraction. This was prepared as follows. The organisms harvested from 11 . medium were suspended in $10 \mathrm{ml} .0 \cdot 1 \mathrm{M}$-phosphate buffer (pH 6.5) and potassium thioglycollate added to $0.01 \mathrm{M}$. An equal volume of Ballotini No. 12 glass beads and two drops of $n$-octanol were added to the suspension and the organisms disrupted by shaking for $20 \mathrm{~min}$. in a Mickle.

* Present address: Chemistry Department, The University, Newcastle upon Tyne 1. 
disintegrator at $3^{\circ}$. The suspension, freed from Ballotini beads, was centrifuged at $30,000 \mathrm{~g}$ for $15 \mathrm{~min}$. and the supernatant fluid centrifuged at $140,000 \mathrm{~g}$ for $1 \mathrm{hr}$. in the Spinco Model $\mathbf{L}$ preparative ultracentrifuge. The particulate material from the latter centrifugation was suspended in $2 \mathrm{ml}$. of $0 \cdot 1 \mathrm{M}$-tris buffer (2-amino-2hydroxymethylpropane-1,3-diol; pH 8.35) containing 0.01 $\mathrm{m}$-potassium thioglycollate; this constituted the enzyme fraction.

UDPG labelled with ${ }^{14} \mathrm{C}$ in the glucose moiety was prepared as described by Smith et al. (1960). The specific activity of the UDPG was $1 \cdot 4 \times 10^{5}$ c.p.m. $/ \mu$ mole.

Radioactivity of the samples. This was determined at infinite thinness in a microthin window gas-flow counter operated in the proportional region. Radioactivity on chromatograms was located with an automatic windowless gas-flow paper chromatogram scanner used in the Geiger region (Atomic Accessories Inc., Valley Stream, New York, U.S.A.).

Isolation of disaccharide. This was done as follows. After the specified incubation period the reaction mixture was heated in a boiling water bath for $2 \mathrm{~min}$., cooled rapidly in ice, centrifuged, and the precipitate discarded. One g. Ultrasorb S.C. 120/240 (British Carbo Norit Union Ltd., West Thurrock, Grays, Essex) 1 g. Hyflo Super-Cel (Johns Manville, New York City) were suspended together in $20 \mathrm{ml} .0 .01 \mathrm{~N}$-formic acid and the suspension poured into a chromatography column of $0.6 \mathrm{~cm}$. diameter. The supernatant fluid from the reaction mixture was diluted with 3 vol. $0.01 \mathrm{~N}$-formic acid and applied to the suitably packed charcoal-SuperCel column which was then washed with $20 \mathrm{ml} .0 .01 \mathrm{~N}$-formic acid. The advisability of maintaining acid conditions during charcoal fractionation of sugars was described by Taylor \& Whelan (1962). The sugars were fractionally eluted from the column with $100 \mathrm{ml}$. volumes of $5 \%(\mathrm{v} / \mathrm{v})$ ethanol in $0.01 \mathrm{~N}$-formic acid, $15 \%(\mathrm{v} / \mathrm{v})$ ethanol in $0.01 \mathrm{~N}$-formic acid and $5 \%(\mathrm{v} / \mathrm{v})$ pyridine in water, respectively. Each fraction was dried in vacuo and for analysis dissolved in $1 \mathrm{ml}$. distilled water.

Chromatography of sugars. This was done on Whatman no. 1 paper in: ethanol + ammonium acetate ( $\mathrm{pH} \mathrm{7.5}$; Paladini \& Leloir, 1952); 2-butanol + acetic acid + acetone + water (Zilliken, Braun \& György, 1955); $n$-butanol + ethanol + water + ammonia (Foster, Horton \& Stacey, 1957); $n$-butanol + acetic acid + water (Partridge, 1948) at $44+16+40$, by vol. The permanganate + periodate spray of Lemieux $\&$ Bauer (1954) was used for locating sugar spots.

Reducing sugars were estimated by the micromethod of Park \& Johnson (1949).

Phosphorus micro-estimations were done by the method of Griswold, Humoller \& McIntyre (1951).

$\beta$-Glucosidase was obtained from Sigma Chemical Co., St Louis, Missouri, U.S.A. $\alpha$-Glucosidase was prepared from baker's yeast by the method of Halvorson \& Ellias (1958); the preparation so obtained was free from $\beta$-glucosidase activity.

\section{RESULTS}

\section{Charcoal + Celite elution pattern}

A reaction mixture consisting of: $9 \mu$ moles ${ }^{14} \mathrm{C}$-labelled UDPG, $1.5 \mu$ mole diphosphopyridine nucleotide (DPN), $45 \mu$ moles $\mathrm{MgCl}_{2}, 2 \mathrm{ml}$. particulate suspension, $0 \cdot 1 \mathrm{M}$-tris buffer ( $\mathrm{pH} 8 \cdot 35$ ) to final volume $9 \mathrm{ml}$., was incubated at $32^{\circ}$ for $60 \mathrm{~min}$., and after heat inactivation was applied to a charcoal + Celite column. A typical 
elution pattern is shown in Fig. 1. A small amount of radioactive material $(0 \cdot 2 \%$ of total) was eluted with $5 \%(v / v)$ ethanol in water and was shown to be glucose by paper chromatography. Thirty-five $\%$ of the total radioactivity was located in the $15 \%(\mathrm{v} / \mathrm{v})$ ethanol-in-water eluate (fraction $\mathrm{A})$; the remaining activity was located in the $5 \%(\mathrm{v} / \mathrm{v})$ pyridine-in-water eluate (fraction $\mathrm{B})$.

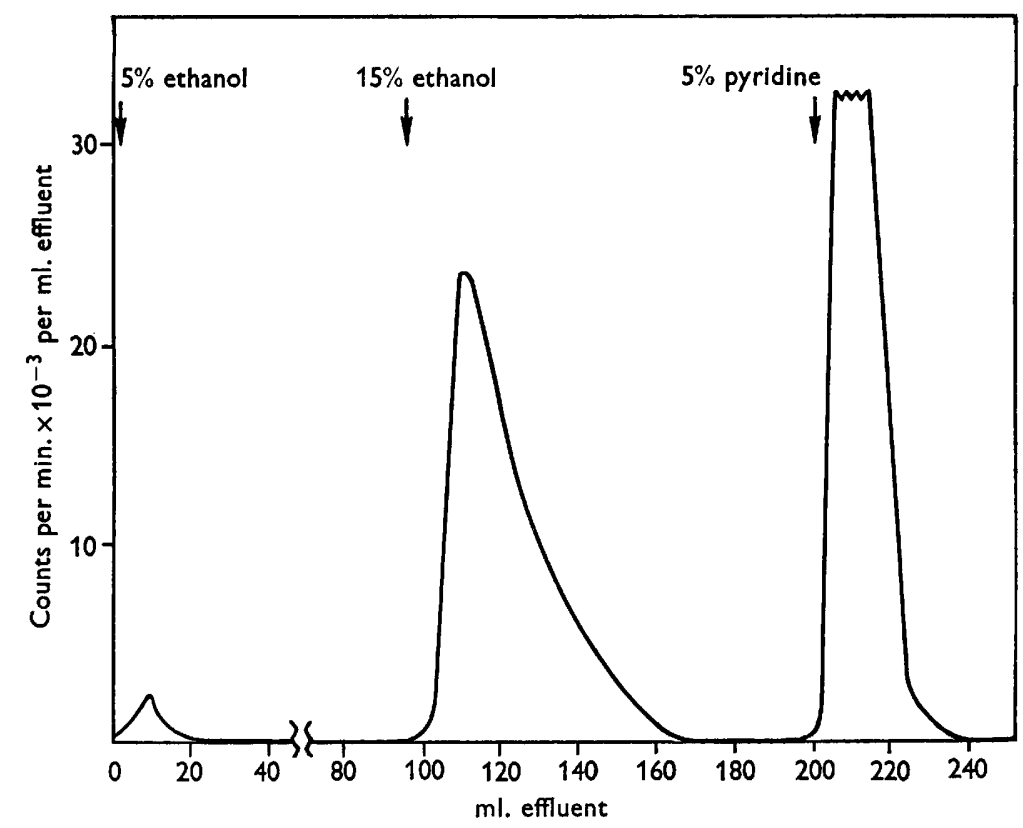

Fig. 1. Charcoal-Celite column elution diagram of radioactive products from the action of the particulate enzyme fraction on ${ }^{14} \mathrm{C}$-UDPG. The aqueous alcohol used for elution contained $0 \cdot 01 \mathrm{~N}$-formic acid.

\section{Analysis of fraction $A$}

Paper chromatography of samples of fraction $\mathbf{A}$ in the various solvents gave a single radioactive component with the $\boldsymbol{R}_{\text {glucose }}$ values shown in Table 1. The radioactive spot was insensitive to spray reagents for reducing sugars but was located with the permanganate + periodate spray (Lemieux \& Bauer, 1954). The labelled material was hydrolysed with $\mathrm{N}-\mathrm{H}_{2} \mathrm{SO}_{4}$ for $1 \mathrm{hr}$. at $100^{\circ}$, neutralized with an excess solid $\mathrm{BaCO}_{3}$, the $\mathrm{BaSO}_{4}$ removed by centrifugation and washed twice with $1 \mathrm{ml}$. distilled water and the combined supernatant fluids and washings were dried under reduced pressure. The hydrolysate was chromatographed on paper in the solvents described above; in all cases they showed glucose to be the sole component. The micromethod of Park \& Johnson (1949) for the estimation of reducing sugars gave zero value on the unhydrolysed material. The liberation of reducing sugar after hydrolysis with $\mathrm{N}-\mathrm{H}_{2} \mathrm{SO}_{4}$ is shown in Table 2 . The labelled material was free from phosphorus as shown by the phosphorus micro-determination. No ultravioletabsorbing material was detected in the labelled compound. That the unhydrolysed material showed no reducing power, its position in paper chromatographic and charcoal column analyses, and the liberation of glucose as sole product of acid hydrolysis, suggest that the compound is a glucopyranosyl-glucopyranoside. 


\section{Nature of the disaccharide linkage}

The nature of the linkage was partially established by hydrolysis with $\beta$-glucosidase; $250 \mu \mathrm{g}$. of labelled disaccharide were incubated at $37^{\circ}$ for $30 \mathrm{~min}$. with $1 \mathrm{mg}$. $\beta$-glucosidase and $0.02 \mathrm{M}$-tris buffer $(\mathrm{pH} \mathrm{7.2})$ to final volume $1 \mathrm{ml}$. The reaction mixture was heated in a boiling water bath for $2 \mathrm{~min}$, centrifuged, and the supernatant fluid concentrated in vacuo. Chromatography of the reaction products in ethanol + ammonium acetate (Paladini \& Leloir, 1952), followed by a scan of the

Table 1. $\boldsymbol{R}_{\text {glucose }}$ values of isolated disaccharide in various paper chromatographic systems

(Values for authentic disaccharides are included for comparison.) Solvents

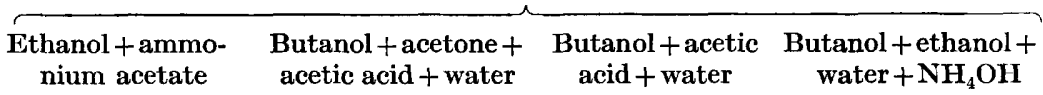

Sugar

Disaccharide

Lactose

Maltose

Cellobiose

Gentiobiose

Trehalose

\begin{tabular}{cccc}
\multicolumn{4}{c}{$\boldsymbol{R}_{\text {glucose }}$ values } \\
\hline 0.83 & $0 \cdot 66$ & $0 \cdot 74$ & $0 \cdot 32$ \\
$0 \cdot 87$ & 0.55 & $0 \cdot 61$ & $0 \cdot 32$ \\
0.91 & $0 \cdot 66$ & $0 \cdot 71$ & $0 \cdot 46$ \\
0.91 & $0 \cdot 61$ & $0 \cdot 71$ & $0 \cdot 43$ \\
0.90 & $0 \cdot 53$ & $0 \cdot 72$ & $0 \cdot 30$ \\
0.98 & $0 \cdot 69$ & $0 \cdot 89$ & 0.50
\end{tabular}

Table 2. The liberation of reducing material from the disaccharide on hydrolysis with $\mathrm{N}-\mathrm{H}_{2} \mathrm{SO}_{4}$

(The theoretical total glucose content of $200 \mu \mathrm{g}$. was calculated from the radioactivity of the disaccharide and the specific activity of the UDPG used $\left(1.4 \times 10^{5}\right.$ c.p.m. $/ \mu$ mole $)$.)

$\begin{array}{cc}\begin{array}{c}\text { Time of hydrolysis } \\ \text { (min.) }\end{array} & \begin{array}{c}\text { Reducing material } \\ \text { as glucose }(\mu \mathrm{g} .)\end{array} \\ 0 & 0 \\ 10 & 49 \\ 20 & 101 \\ 30 & 150 \\ 60 & 200 \\ 90 & 200 \\ 120 & 215\end{array}$

Theoretical for disaccharide: 200

chromatogram with the windowless gas-flow scanner, showed the presence of glucose, unchanged disaccharide and a third component with an $R_{\text {glucose }}$ value of 0.35 (Fig. 2). This latter component was eluted from the chromatogram with water and had a reducing value equivalent to $15 \%$ of the total glucose liberated by hydrolysis with $\mathrm{N}-\mathrm{H}_{2} \mathrm{SO}_{4} \cdot \alpha$-Glucosidase had no effect on the disaccharide when incubated with it under the optimal conditions specified by Halvorson \& Ellias (1958). The particulate enzyme fraction did not produce the disaccharide described when incubated with UDPG $+{ }^{14} \mathrm{C}$-glucose, UDPG $+{ }^{14} \mathrm{C}$-glucose-1-phosphate, ${ }^{14} \mathrm{C}$-glucose alone or with free ${ }^{14} \mathrm{C}$-glucose-1-phosphate alone. 


\section{Analysis of Fraction $B$}

Paper chromatography of fraction B in the ethanol + ammonium acetate solvent of Paladini \& Leloir (1952) showed a single ultraviolet-absorbing component with an $R_{F}$ value identical with that of UDPG; all the radioactivity was associated with this one component. Hydrolysis of this material in $0.01 \mathrm{~N}-\mathrm{HCl}$ as described by Paladini \& Leloir (1952), and chromatography of the resultant sugars in the solvents listed above, showed the presence of both glucose and galactose. A sample of the hydrolysed material was chromatographed in $n$-butanol + pyridine + water for four successive periods of $16 \mathrm{hr}$. each, the chromatogram being dried between each run. Complete separation of glucose and galactose was achieved by this means and the ratio of glucose: galactose was $1: 4$ in terms of radioactivity.

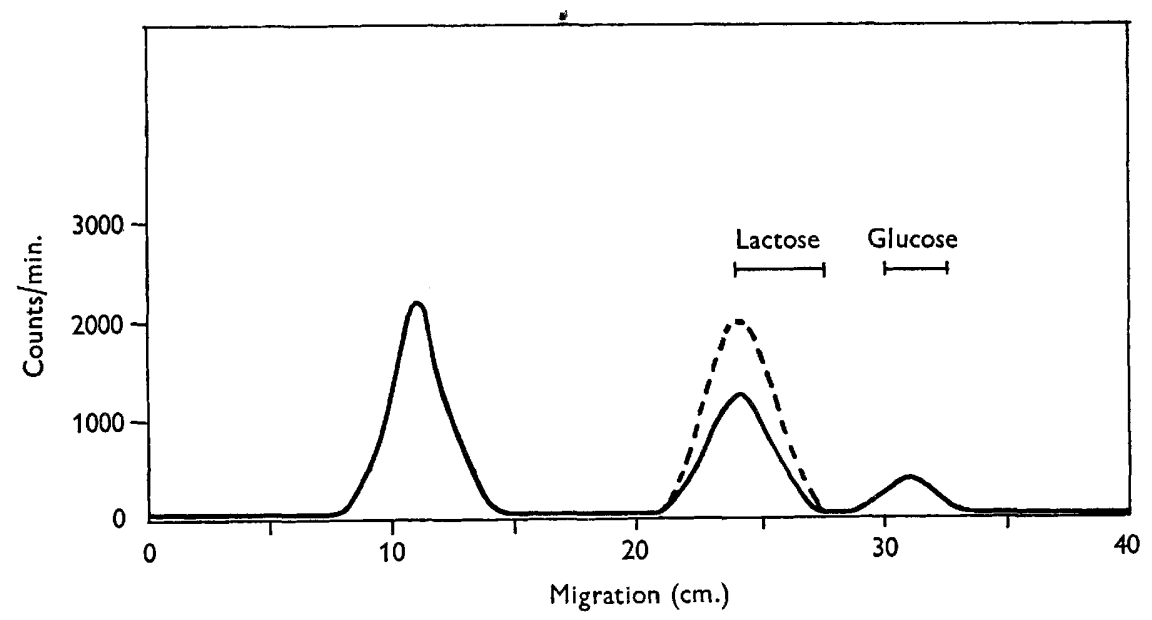

Fig. 2. Scan of radioactivity on chromatogram of the products of $\beta$-glucosidase action on the disaccharide. The glucose and lactose markers are indicated by bars. The broken curve is from the control reaction of the disaccharide without $\beta$-glucosidase.

\section{DISCUSSION}

The structure proposed for the material synthesized by Streptococcus pneumoniae type VIII in the reaction described is glucopyranosyl-glucopyranoside, in which at least one of the linkages is of the $\beta$ configuration. The reaction involved in its formation may be formulated as follows:

\section{UDPG + UDPG $\rightarrow$ glucopyranosyl-glucopyranoside 1 \\ UDPGalactose}

The disaccharide nature of the molecule may be deduced from the following observations: (1) The material is eluted from a charcoal-Celite column with $15 \%$ $(\mathrm{v} / \mathrm{v})$ ethanol in water under acid conditions (Taylor \& Whelan, 1962). (2) The location of the compound on paper chromatography is that of a disaccharide unit, with $R_{F}$ values closely approximating those of known disaccharides in most solvent systems. French \& Wild (1953) showed that the number of monosaccharide units in a series of oligosaccharides determines their chromatographic position and that a 
plot of $\log R_{F} /\left(1-R_{F}\right)$ against the degree of polymerization gives a straight line. The non-reducing nature of the molecule, the liberation of glucose on acid hydrolysis, and the enzymatic cleavage with $\beta$-glucosidase, would suggest a $\mathrm{C} 1$ to $\mathrm{C} 1$ linkage within the molecule, where at least one of the glucosyl residues is linked in the $\beta$-configuration.

The component with an $\boldsymbol{R}_{\text {glucose }}$ value of 0.35 in ethanol + ammonium acetate, which was produced on incubation with $\beta$-glucosidase, may be a higher reducing oligosaccharide obtained by transglycosylation. The transient formation of glucose oligosaccharides during the hydrolysis of cellobiose and other $\beta$-glucosides was shown by Crook \& Stone (1957). Although the disaccharide is not attacked by $\alpha$-glucosidase, it cannot be inferred that both linkages are thus of the $\beta$ configuration. Halvorson \& Ellias (1958) showed that $\alpha$-glucosidase does not affect trehalose ( $\alpha$-1-glucopyranosyl- $\alpha$-1-glucopyranoside).

Synthesis of the disaccharide is specific for UDPG, as UDPG in combination with glucose or glucose-1-phosphate will not produce the same material. Other disaccharides and oligosaccharides are, however, produced by such reactions, the natures of which are currently under investigation. Neither free glucose nor glucose1-phosphate, single or in combination, will produce the disaccharide.

The conversion of UDPG to UDPGalactose by the particulate enzyme fraction is of interest as a demonstration of UDPGalactose-4-epimerase activity associated with particulate material. It should be noted that the equilibrium is in favour of UDPGalactose production as distinct from the reactions discussed by Kalckar \& Maxwell (1958). The biosynthesis of the disaccharide is not specific for any one type of pneumococcus and has also been achieved with particulate material from pneumococci of types II and III. It is suggested that the reaction may be involved in the formation of pneumococcal cell-wall polysaccharide as distinct from the cellular or somatic polysaccharide, which does not contain glucose as a constituent sugar (Smith, Mills, Harper \& Galloway, 1957).

This work was supported by Grant E-1018 (C6) from the National Institute of Allergy and Infectious Diseases, National Institutes of Health of the United States Public Health Service. The authors wish to thank Miss Ingbritt Blomstrand for expert technical assistance.

\section{REFERENCES}

Crook, E. M. \& Stone, B. A. (1957). The enzymic hydrolysis of $\beta$-glucosides. Biochem. $J$. $65,1$.

Foster, A. B., Honton, D. \& Stacey, M. (1957). Amino sugars and related compounds. Part II. Observations on the acidic hydrolysis of derivatives of 2-amino-2-deoxy-Dglucose (D-glucosamine). J. chem. Soc. p. 81 .

FrENCH, D. \& WiLD, G. M. (1953). Correlation of carbohydrate structure with papergram mobility. J. Amer. chem. Soc. 75, 2612.

Griswold, B. L., Humoller, F. L. \& McIntyre, A. R. (1951). Inorganic phosphate and phosphate esters in tissue extracts. Analyt. Chem. 23, 192.

Halvorson, H. \& Ellias, L. (1958). Purification and properties of an $\alpha$-glucosidase of Saccharomyces italicus y1225. Biochim. biophys. Acta, 30, 28.

Kalckar, H. M. \& Maxwell, E. S. (1958). Biosynthesis and metabolic function of uridine diphosphoglucose in mammalian organisms and relevance to certain inborn errors. Physiol. Rev. 38, 77. 
Lemievx, R. U. \& BAUER, H. F. (1954). Spray reagent for the detection of carbohydrates. Analyt. Chem. 26, 920.

Mirls, G. T. \& Smith, E. E. B. (1962). Biosynthesis of pneumococcal capsular polysaccharides. Fed. Proc. (in the Press).

Paladini, A. C. \& Lelork, L. F. (1952). Studies on uridine-diphosphate-glucose. Biochem. $J .44,402$.

Park, J. T. \& Johnson, M. J. (1949). Submicrodetermination of glucose. J. biol. Chem. $181,149$.

Partridge, S. M. (1948). Filter paper partition chromatography of sugars. Biochem. $J$. 42, 238.

Smith, E. E. B., Galloway, B. \& Mills, G. T. (1961). The enzymic synthesis by a pneumococcal extract of a serologically reactive polymer from uridine diphosphate galacturonic acid. Biochem. biophys. Res. Comm. 4, 420.

Smith, E. E. B., Milis, G. T. \& Bernheimer, H. P. (1961). Biosynthesis of pneumococcal capsular polysaccharides. I. Properties of the system synthesizing type III capsular polysaccharide. J. biol. Chem. 236, 2179.

Smith, E. E. B., Mirls, G. T., Bernheimer, H. P. \& Austrian, R. (1960). The synthesis of type III pneumococcal capsular polysaccharide from uridine nucleotides by a cellfree extract of Diplococcus pneumoniae type III. J. biol. Chem. 235, 1876.

Smith, E. E. B., Mills, G. T., Harper, E. M. \& Galloway, B. (1957). The cellular polysaccharide of a type II non-capsulated pneumococcus. J. gen. Microbiol. 17, 437.

TAYlor, P. M. \& Whelan, W. J. (1962). An improved method of fractionating sugars on charcoal. Chem. Ind., Lond. p. 44.

Zilliken, F., Braun, G.A.\& GYörGY, P. (1955). Gynaminic acid. A naturally occurring form of neuraminic acid in human milk. Arch. Biochem. 54, 564. 